\title{
INFLUENCE OF THE PANDEMIC ON THE BEST ROMANIAN HANDBALL LEAGUES FOR SENIORS
}

\author{
Cristina VĂRZARU ${ }^{1 *}$, Virgil TUDOR ${ }^{1}$ \\ ${ }^{1}$ National University of Physical Education and Sport, Faculty of Physical Education and Sport, Bucharest, \\ Romania \\ *Corresponding author: cristina.varzaru@ frh.ro
}

https://doi.org/10.35189/dpeskj.2021.60.4.8

\begin{abstract}
The current paper aims to present the situation of COVID-19 cases recorded among the teams participating in Liga Florilor MOL and Liga Zimbrilor (the best senior leagues in Romania), the monthly distribution of the number of no-shows due to coronavirus and the analysis of teams' adaptability to the new anti-COVID-19 regulations as regards the number of sanctions received for non-compliance with these rules. The novel coronavirus affected all teams participating in Liga Florilor MOL and Liga Zimbrilor. In total, 365 people including players and staff were infected with SARS CoV-2 during this season. Eight teams were in the situation of not being able to participate in handball tournaments, and 24 games were decided at the green table due to COVID-19, meaning 5.86\% of the total number of games scheduled for the best men's and women's leagues in the 2020-2021 season. The Romanian Handball Federation organized 207 "bubble system" tournaments for all competitive categories, of which 31 were organized for Liga Florilor MOL (17) and Liga Zimbrilor (14). Throughout the season, the teams successfully adapted to the new rules against the spread of the SARS CoV-2 virus. The sanctions imposed for non-compliance with these rules, excepting the games ended 10:0, were extremely low in numbers. A single pecuniary penalty was applied, which was doubled by an exclusion from that tournament. In addition, a single warning was given to a team that violated the ban on using the locker room inside the sports hall.
\end{abstract}

Keywords: handball, pandemic, women, men.

\section{Introduction}

"For the third time in as many decades, a zoonotic coronavirus has crossed species to infect human populations." (Perlman, 2020, p. 760)

"COVID-19 is a part of family viruses causing diseases in both animals and humans." (Setiawan et al., 2020, p. 377) Although this new phenomenon is daily mentioned in the media, it is still little studied for the time being (Feofanov \& Koroleva, 2021).

The pandemic does not take into account geography, has a global reach and no continent has escaped its "clutches" (World Health Organization, 2019). According to Memish et al. (2019), musical, religious or sporting mass gatherings have undoubtedly contributed to the spread of infectious diseases.

The first report on the appearance of the new virus was identified in Wuhan city, China, at the end of 2019. The pandemic has spread around the world in different ways, and "the countries entered a pandemic situation at different times" (Tsiring \& Ponomareva, 2021, p. 339). As a result, quarantine and isolation periods have been imposed on citizens (MonLopez et al., 2020). The first case of COVID-19 was reported in Romania on 26 February 2020. Considering the evolution of the epidemiological situation caused by the rapid proliferation of the disease (Da Silva Musa et al., 2020), the President of Romania signed (on 
16 March 2020) the decree regarding the establishment of the state of emergency on the territory of Romania for a period of 30 days.

The coronavirus crisis not only has had a deep impact on our lifestyles and socialising patterns (Kucheryavenko \& Beletskaya, 2020), but one of the groups most clearly affected by the COVID-19 pandemic are elite athletes due to dramatic changes to the world of sports (Hakansson et al., 2020). Ratten (2020) states that "the sport sector has been especially influenced by the COVID-19 crisis in a way that has never been seen before" (p. 1379). The measures imposed by the local authorities responsible for combating SARS CoV-2 included, among others, the cessation of all sports competitions during the state of emergency. The restrictions were necessary in order to reduce infection rates (Hermassi et al., 2020).

The novel coronavirus found everyone unprepared, including the authority responsible for organizing handball activities in Romania. The rules existing in our country when the SARS CoV-2 virus emerged did not include any specifications for special situations such as the interruption of championships without the possibility of playing them on the field. The situation was the same in all European federations affiliated to the European Handball Federation, and this conclusion was reached during an extraordinary online meeting organized by the European Handball Federation at the beginning of the COVID-19 pandemic.

In this context, the Romanian Handball Federation - the authority responsible with the organization and control of all handball competitions in Romania - was forced to align with the measures dictated at national level and stopped, by decision of the Administration Board, all handball competitions in the 2019-2020 season starting on 13 March 2020.

Although the decision made by the Executive Body of the Romanian Handball Federation initially referred to a short and limited period with no changes in sports competitions, the extension of the state of emergency and its subsequent replacement by the state of alert caused the aforementioned federation to stop all handball competitions scheduled for the 2019-2020 season, excepting the First-League Promotion Tournament and the Romanian Men's and Women's Senior Cup, which were postponed and planned to be played at the beginning of the new season (2020-2021), depending on the date from which the local authorities responsible for the COVID-19 situation would have decided to reopen sports competitions on the Romanian territory.

Since the appearance of the coronavirus disease in Romania, the activity of the Romanian Handball Federation's departments and commissions has been extremely intense due to the urge need to adapt to the new times generated by the worldwide spread of SARS CoV-2. The regulations were widely debated by relevant people and then amended and supplemented with rules for special situations and a medical protocol for organizing and conducting handball activities so as to minimise the risk of COVID-19 infection.

The process was extremely winding and, although the people involved in the handball activity had a lot of experience, they were facing such a situation for the first time.

Having as clear strategy to plan, organize and especially play all handball competitions in the coming season 2020-2021, one of the most important decisions made by the Romanian Handball Federation was not to postpone any handball game due to suspicious or confirmed cases of coronavirus. Thus, the team that does not show up for a game due to COVID-19 loses the game 10:0. Even though much discussion was against this rule, it proved to be 
extremely beneficial for the good development and timely completion of the games within the deadline set by the European Handball Federation for the 2020-2021 season.

\section{Research purpose}

The current paper aims to present the situation of COVID-19 cases recorded among the teams participating in Liga Florilor MOL and Liga Zimbrilor (the best senior leagues in Romania), the monthly distribution of the number of no-shows due to coronavirus and the analysis of teams' adaptability to the new anti-COVID-19 regulations as regards the number of sanctions received for non-compliance with these rules.

\section{Methodology}

The research was conducted on the teams participating in the best senior leagues managed by the Romanian Handball Federation in the 2020-2021 season. Accounting for COVID-19 cases was possible due to the following rule implemented at the outbreak of the virus: even if it was only a period of local training sessions, in the event of a suspected case of COVID-19, the team was asked to notify the Romanian Handball Federation within a maximum of two hours about that possible case and then supplement the information when the COVID-19 case was confirmed or denied.

The graphical method was used to highlight: the number of COVID-19 infections in the 2020-2021 season - women's teams; the number of COVID-19 infections in the 2020-2021 season - men's teams; the monthly distribution of the number of no-shows due to COVID-19; the teams affected by COVID-19; the number of games lost 10:0 due to coronavirus.

Among the mathematical and statistical indicators used in this research, we mention the sum, mean, minimum and maximum values.

\section{Results}

Since 13 May 2020, the state of alert has been established in Romania and continues today. The decisions of local authorities on the measures imposed during the state of alert require the national sports federations to carry out their activities in accordance with the Joint Order of the Ministry of Youth and Sport/Ministry of Health, a document that has been amended several times in the last 12 month, but the "bubble system" tournaments - the only possible form of playing sports competitions - has remained unchanged, as well as the obligation for all participants to take the COVID test before any tournament; initially, this was an RT-PCR test but subsequently the rapid antigen test has also become possible to be used. In addition, if the duration of a tournament exceeded 14 days, the teams had to repeat the RT-PCR test.

By limiting contact with the outside world, the "bubble system" is known to reduce the risk of infection (Ogasawara et al., 2021). Testing frequency should be determined not only for the early detection of a person's disease but also to facilitate an athlete's efforts to minimise the potential spread of the virus to other participants (DiFiori et al., 2020). 
These two conditions were fully respected by the Romanian Handball Federation and its affiliated members but at the same time raised many problems for those involved due to high implementation costs and the complexity of tournament scheduling, given that other 5 men's teams and 5 women's teams were also participating in the European cups organized by the European Handball Federation in the 2020-2021 season, which are generally scheduled in parallel with local competitions, with priority for European ones.

Each team's athletes had to take RT-PCR tests within 48 hours prior to each tournament. Then, according to national sports rules, if the tournament lasted more than 14 days, players had to test again during the tournament. Moreover, if a player showed COVID-19 symptoms during a tournament, the whole team had to repeat the RT-PCR test.

The new 2020-2021 competition season was scheduled to start on August 19 for men and August 27 for women with the First-League Promotion Tournament and the Romanian Cup as a preview, one week before.

Due to both the pandemic situation at that time and the fact that, for a very long time, teams could not even train together indoors but only outdoors in small groups, without the handball and without any contact specific to the game, the initial planning could not be respected, which is why the established schedule was postponed.

The first handball tournament, actually representing the first indoor competition played in our country since the reopening of sports activities, was the Romanian Women's Cup held between 3 and 6 September 2020. Liga Florilor MOL started more than 1 month later and was held from 14 to 15 October due to the European Handball Federation's schedule for CSM Bucharest and SCM Rm. Vâlcea in the Champions League.

The new season of Liga Zimbrilor started in the period 15-17 September. In the preview of this tournament, the First-League Promotion Tournament and the Romanian Cup took place, all three competitions being included in a single "bubble system" tournament that started on 11 September from a desire to reduce the costs of RT-PCR testing before the tournament.

Throughout the competition season for all age categories, the Romanian Handball Federation planned, organized and supervised 207 tournaments, of which 14 tournaments for Liga Zimbrilor and 17 tournaments for Liga Florilor MOL. The Romanian Handball Federation was also the first federation for indoor sports in Romania to open the championships dedicated to juniors, while other federations decided not to take any risk and did not organize any competition for juniors during the entire 2020-2021 season.

Although the initial playing system for the men's league included play-off/out phases, the Romanian Handball Federation decided to give them up because of the impossibility to schedule all matches until the date imposed by the European Handball Federation (early June). Thus, the approved new system only included games played in the "home and away" system, the same used for the best women's league.

The negative effects of the global pandemic and the change of leadership in some places due to the elections organized throughout Romania led to serious financial problems and the impossibility to continue the competitions for two teams in the first league, namely a men's team and a women's team that withdrew at different moments of those competitions. But the withdrawal occurred before $50 \%+1$ of the season's games were played, so all their previous results were cancelled. 
The 17 women's tournaments included 210 games. The tournaments had a different number of rounds, from a single-round tournament up to a maximum of 4 rounds, depending on the programmes of women's national team and club teams in the European cups. Because two teams were participating in the Champions League competition since September, CSM Bucharest and SCM Rm. Vâlcea had to play the games in the European competition every weekend. So, the Romanian Handball Federation was in the situation of planning many oneround tournaments of the national championship instead of 3-4 rounds, which would have reduced the number of tournaments and thus the costs of RT-PCR testing. At the time of writing this paper, 199 games had been played, which were included in the present research.

The 14 men's tournaments consisted of 210 games. The tournaments had a different number of rounds, from a single-round tournament up to a maximum of 6 rounds, depending on the programmes of men's national team and club teams in the European cups. The planning of men's tournaments was a little easier to achieve because no Romanian team had qualified for the Champions League competition, and for the rest of the European cups, the system proposed by the European Handball Federation did not include a weekly frequency of European matches.

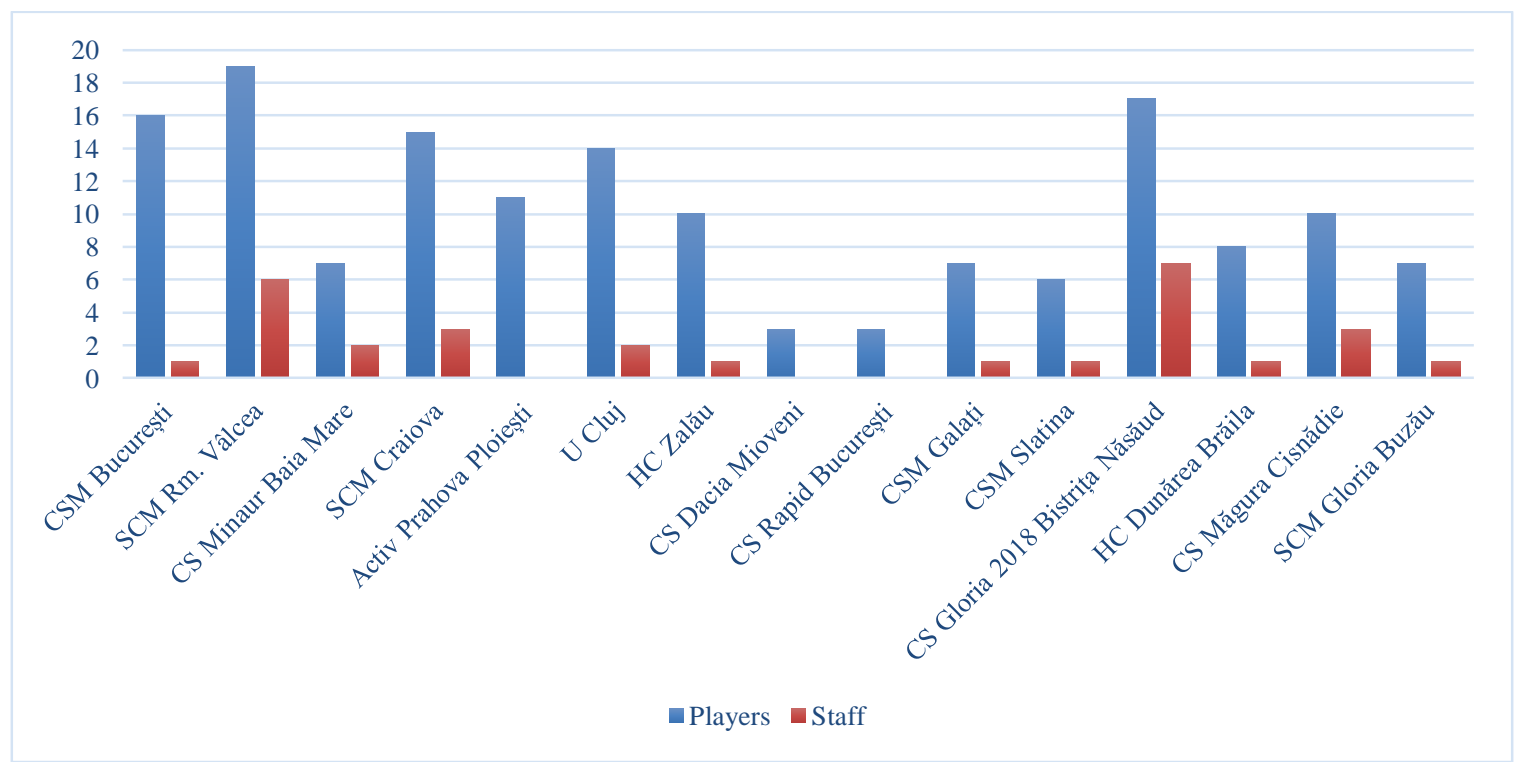

Figure 1. Number of COVID-19 infections during the 2020-2021 season - Women's teams

In Liga Florilor MOL, all 15 teams had to deal with the new virus infections (Figure 1). In total, 182 people were reported by the COVID officers of the teams to get infected with the novel coronavirus from October 2020 to date as follows: 29 team staff members (coaches, team managers, medical professionals, etc.) and 153 players. Five teams had over $75 \%$ of the team members infected with the novel coronavirus, and the most affected teams were SCM Rm. Vâlcea and CSM Gloria 2018 Bistrița Năsăud with 25/19 players and 6 staff members, respectively 24 people confirmed with COVID-19, of which 17 players and 7 staff members. They were followed by SCM Craiova, CSM Bucharest and U Cluj with 17 (15 players and 2 staff members), 18 (17 players and 1 staff member) and 16 (14 players and 2 staff members) cases of SARS CoV-2. At the opposite pole, the lowest number of people infected with 
coronavirus was in the Dacia Mioveni and CS Rapid Bucharest teams, each informing the Romanian Handball Federation about 3 confirmed cases, all among the players.

The spread of the new coronavirus in the Măgura Cisnădie team increased to 13 cases, of which 10 players and 3 staff members. Activ Prahova Ploiești and HC Zalău had 11 cases of COVID-19 each; in the former team, all were counted among the players, while in the latter, 1 staff member and 10 players got infected with the virus.

Both CS Minaur Baia Mare and HC Dunărea Brăila informed the Romanian Handball Federation about 9 cases of COVID infection, while CSM Galați and CSM Gloria Buzău announced 8 cases each during the 2020-2021 competition season.

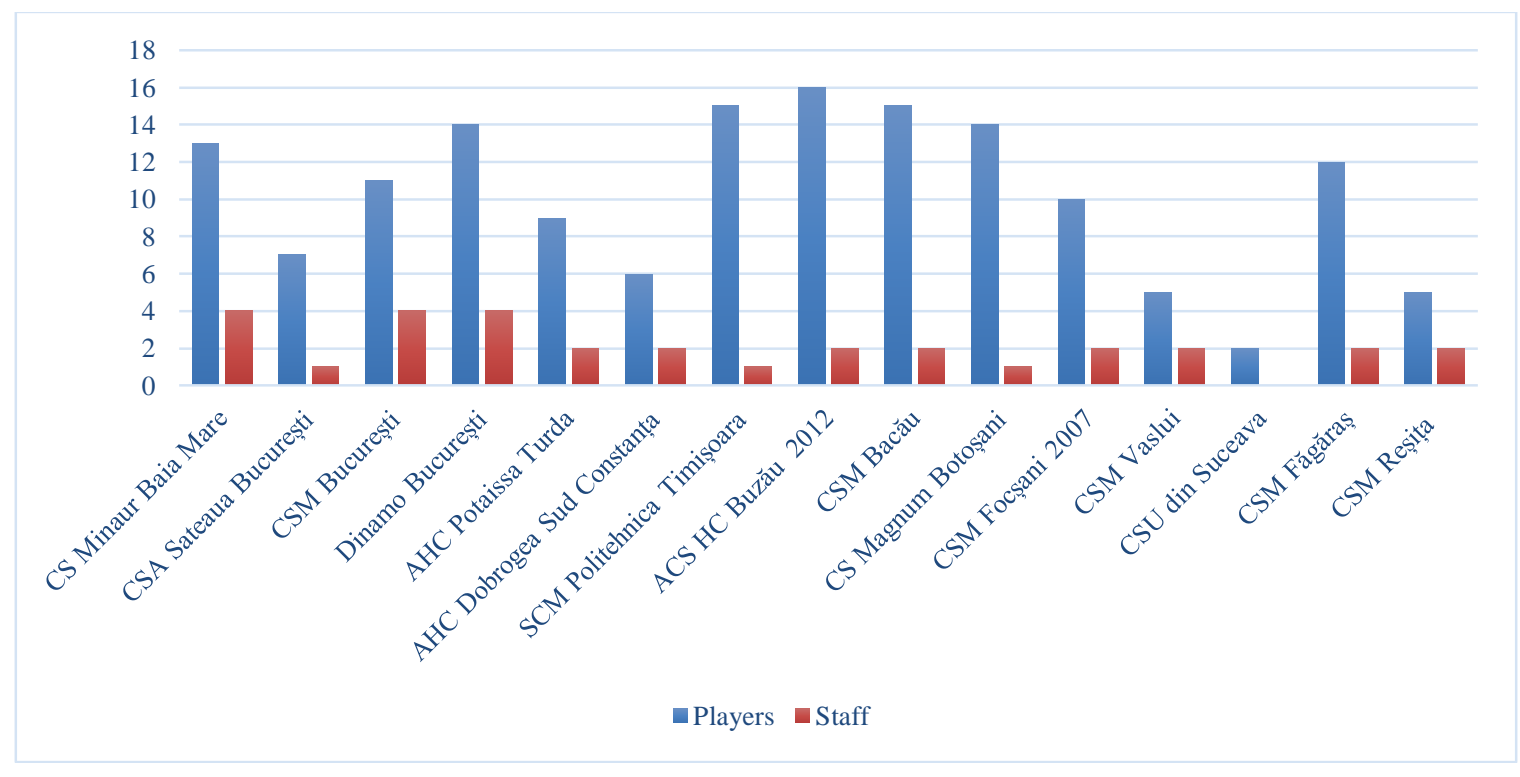

Figure 2. Number of COVID-19 infections during the 2020-2021 season - Men's teams

In Liga Zimbrilor, no team escaped COVID-19 infections among its members (Figure 2). The number of people infected with the new virus increased to 183, of which 154 players and 29 staff members. The most affected teams were CS Dinamo Bucharest and ACS HC Buzău 2012, each with 18 infected people; in the former team, 14 players and 4 staff members got infected with the virus, and in the latter, the number of players infected with SARS-CoV-2 was 16, while the remaining 2 cases were counted among staff members. CS Minaur Baia Mare and CSM Bacău closely followed the aforementioned teams, each with 17 infections. The lowest number of people infected with coronavirus was in the CSU Suceava teams, each informing the Romanian Handball Federation about 2 confirmed cases among the players.

The SCM Politehnica Timișoara team informed the Romanian Handball Federation about 16 positive cases, of which 15 players and 1 staff member.

CSM Bucharest and CS Magnum Botoșani had 15 cases of COVID-19 as follows: 11 players and 4 staff members from CSM Bucharest and 14 players and 1 staff member from CS Magnum Botoșani.

CSM Făgăraș was also affected by the spread of SARS-CoV-2, 12 players and 2 staff members being positive to the virus in the 2020-2021 season. 
CSM Focșani 2007 had 12 positive cases of COVID-19, of which 10 players and 2 staff members, while AHC Potaissa Turda had 11 team members infected with the new virus, of which 9 players and 2 staff members.

Steaua Bucharest and AHC Dobrogea Sud Constanţa informed the national federation about 11 positive cases of COVID-19 each, while CSM Vaslui and CSM Reșița announced 7 cases each during the 2020-2021 competition season.

\section{No-shows at tournaments due to the COVID-19 situation}

The total number of games lost 10:0 for no-show due to COVID-19 is 24, meaning 5.86\% of all 409 games played at that moment in the best Romanian men's and women's handball leagues. Twenty-one of these games were registered in Liga Zimbrilor, while another 3 were registered in Liga Florilor MOL. As a percentage, 10\% of men's league games were lost at the green table, while in the women's sector, the percentage was only $1.5 \%$ from the total of 199 games played until then.

The total number of teams that were forced not to show up at a tournament due to coronavirus was 5 in the male sector and 3 in the female sector.

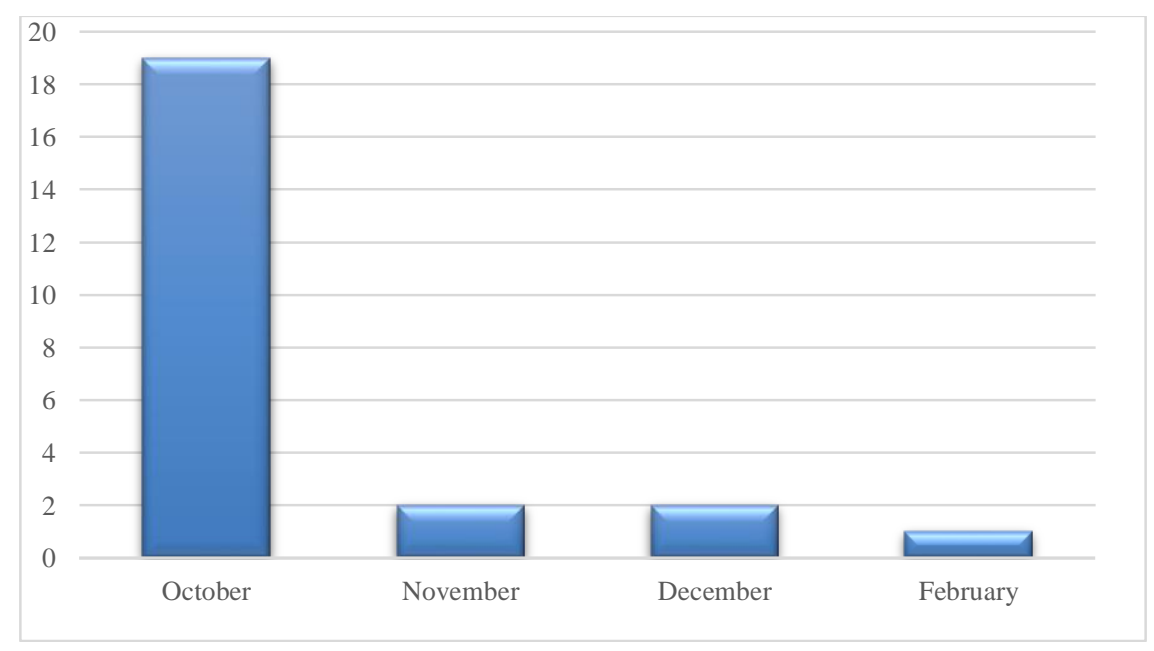

Figure 3. Monthly distribution of the number of no-shows due to COVID-19

As can be seen in Figure 3, the most difficult month was October 2020. Unfortunately, the most affected teams were from the men's sector, as the tournament held in October planned 6 rounds. In this tournament, CS Magnum Botoșani could not show up for the entire tournament, losing 6 games with the score 10:0 due to the COVID pandemic, while CSM Bacău reached only the final game of the tournament, when the players and staff infected with COVID-19 had passed the quarantine period. This was possible due to another new rule approved by the Romanian Handball Federation, which allows any team who could not show up from the start of the tournament to return to competition as soon as its members get out of the 14 days of quarantine imposed on people infected with the novel coronavirus, provided that they present the green light from the Public Health Department, the authority responsible in this matter. 
In the same tournament, CSM Focșani 2007 was excluded after only one round due to violating the rule on the announcement of a suspicions case, which was later confirmed positive to SARS CoV-2, and therefore lost the next 5 games with the score 10:0. SCM Politehnica Timişoara was another team that seriously suffered due to coronavirus, the team losing 4 games with the score 10:0 in three different tournaments.

In the women's sector, HC Zalău, CS Gloria 2018 Bistriţa Năsăud and CSM Slatina lost one game each due to COVID-19, which forced them not to show up at different tournaments that were scheduled in a single round.

The teams affected by COVID-19 and the number of games lost 10:0 due to coronavirus are shown in Figure 4.

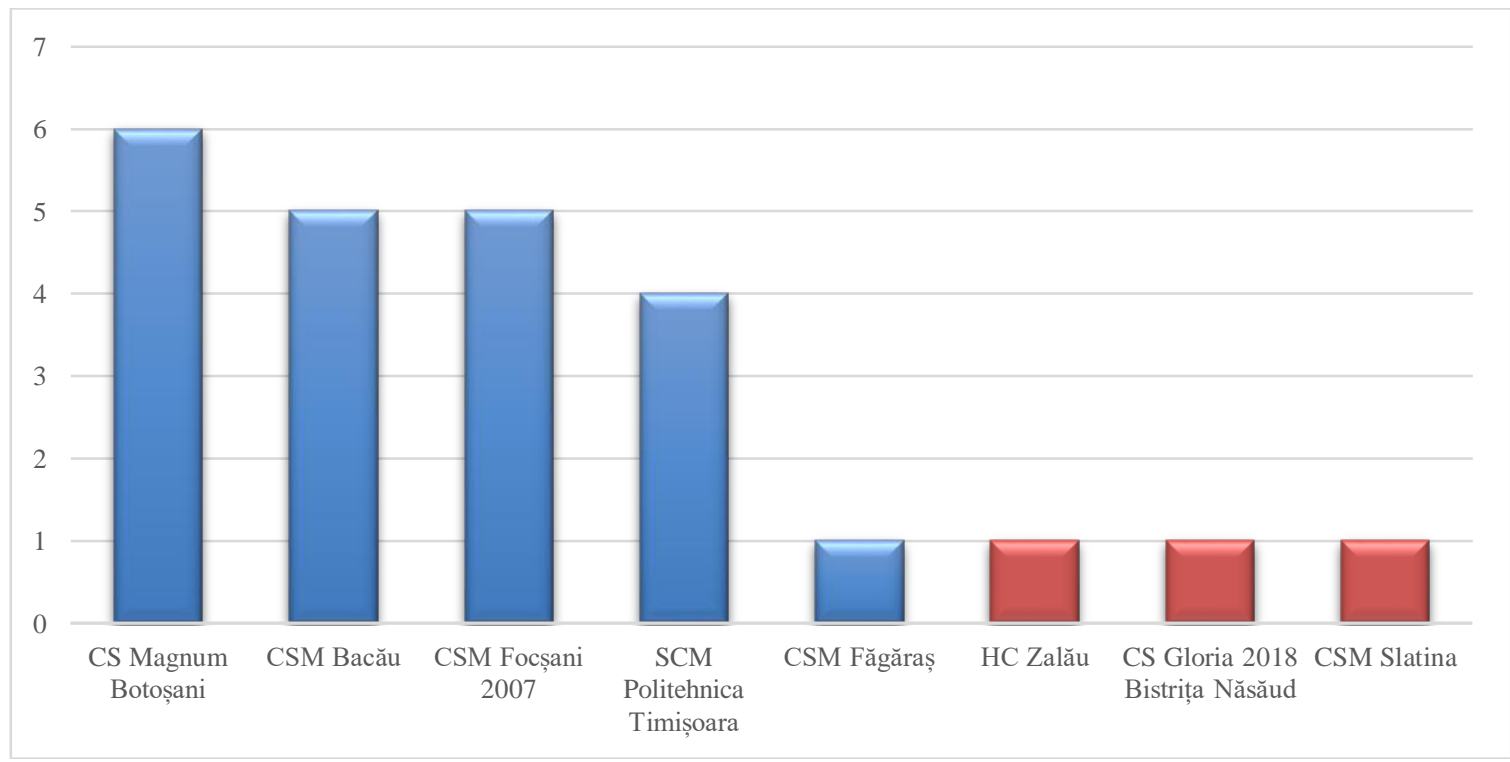

Figure 4. Teams affected by COVID-19 and the number of games lost 10:0 due to coronavirus

Teams' adaptability to the new anti-COVID-19 regulations as regards the number of sanctions received for non-compliance with these rules

Along with the new anti-COVID-19 regulations imposed in the medical protocol for the organization and conduct of handball competitions, a set of sanctions was provided for noncompliance with the measures implemented to reduce the risk of COVID-19 infection. In addition to the rules on losing the game with the score 10:0 for no-show of the teams at tournaments due to coronavirus (1) and breaching the obligation to inform the federation about the occurrence of a suspected case of COVID-19, whether this happens during a tournament or while training at a local level (2) (rules that have been previously stated and debated), other sanctions refer to breaching the interdiction to visit another team's representatives (3) or leaving the "bubble" - the hotel (4) for a purpose other than going to the sports hall, breaching the interdiction to use the locker room in the sports hall (5) and breaching the obligation to wear protective masks, keep social distancing and use individual hydration bottles (6). 
Throughout the season, the teams seemed to have successfully adapted to the new requirements and understood that strict compliance with the regulations would significantly reduce the damage caused by SARS CoV-2. No fines were imposed on teams for violating the anti-coronavirus rules listed above from 2 to 6 . Only one warning was issued against a men's team that did not respect the rule of not using the locker room after a game. A pecuniary sanction was applied to CSM Focșani that did not comply with rule no. 2 above, together with the exclusion of the team from that tournament. Most of the sanctions (10) were applied to the teams for not showing up to play a game due to COVID-19 infection.

\section{Conclusion}

The coronavirus pandemic strongly affected sports worldwide and therefore in our country too in 2020. For a period of more than 6 months, any sports competition in Romania was closed, in the sense that it could not be held even for training. The resumption of sports competitions was established by the authorities in very difficult conditions, involving huge financial efforts from all sports structures participating in handball competitions but also from the Romanian Handball Federation. The constant struggle against this new virus that has so many unknowns and mutations has left its mark on team performance because, although the imposed rules were followed with great discipline by everyone, no team was spared from COVID-19 infection. The repeated elimination of a number of players from the same team at a time made it extremely difficult to plan training so as to reach the desired sports shape. The proposed system for conducting sports competitions in Romania - the "bubble system" tournaments - made even more difficult the task of team leaders in financial terms but also as regards coherence in planning training sessions.

The novel coronavirus affected all teams participating in Liga Florilor MOL and Liga Zimbrilor, some of them being severely affected by the number of unavailable players due to COVID-19. In total, 365 people including players and staff were infected with SARS CoV-2 during this season. Coincidentally, the number of COVID-19 cases was almost equally divided between the female and male sectors.

Eight teams were in the situation of not being able to participate in different tournaments organized in the domestic handball league, and 24 games were decided at the green table due to COVID-19, meaning 5.86\% of the total number of games scheduled for the best men's and women's leagues in the 2020-2021 season.

The Romanian Handball Federation organized 207 "bubble system" tournaments for all competitive categories, of which 31 were organized for Liga Florilor MOL (17) and Liga Zimbrilor (14). The number of rounds included in each tournament ranged from 1 to a maximum of 6 , depending on the international calendar of club teams and national teams.

Throughout the season, the teams successfully adapted to the new rules against the spread of the SARS CoV-2 virus and understood to follow them very strictly. The sanctions imposed for non-compliance with these rules, excepting the games ended 10:0, were extremely low in numbers. A single pecuniary penalty was applied, which was doubled by an exclusion from that tournament due to concealing the occurrence of a COVID-19 case. In addition, a single warning was given to a team that violated the ban on using the locker room inside the sports hall where the tournament took place. 
The 2020-2021 competition season, which is now coming to an end, can easily be called a season of survival over which handball has passed with immense efforts but has passed well. We are far from being able to assess the negative effects of this pandemic but we can say that we are satisfied that all competitions planned at junior and senior levels will be played and completed on the field, in the extremely difficult and unforeseen conditions we have faced.

The Romanian Handball Federation is already preparing for a new season that is scheduled to begin at the end of August. It is very clear to all of us that we are far from completely getting rid of the novel coronavirus and the restrictions imposed to combat its spread. Thus, the process of planning the new season and amending the regulations for the new season is in full swing. Using the experience gained in a year spent with the COVID-19 pandemic among us, the Romanian Handball Federation tries to create for the teams participating in handball activities in Romania a framework as close to normal as possible, without endangering the health of the participants.

\section{Authors' Contribution}

Both authors have equally contributed to this study and should be considered as main authors.

\section{References}

Da Silva Musa, V., dos Santos, W. R., Menezes, R. P., Costa, V., Aquino, R., \& Menezes, R. P. (2020). COVID-19 and Brazilian handball coaches: Impact on training prescription and professional learning. Motriz, Rio Claro, 26(4): e10200127. https://doi.org/10.1590/S1980-65742020000400127

DiFiori, J. P., Green, G., Meeuwisse, W., Putukian, M., Solomon, G. S., \& Sills, A. (2020). Return to sport for North American professional sport leagues in the context of COVID19. British Journal of Sports Medicine, 55(8), 417-421. http://dx.doi.org/10.1136/bjsports-2020-103227

Feofanov, V. N., \& Koroleva, J. A. (2021). Peculiarities of working as an educational psychologist during the coronavirus pandemic. European Proceedings of Social and Behavioural Sciences, 107, 496-504. https://doi.org/10.15405/epsbs(2357-1330).2021.5.1

Hakansson, A., Jonsson, C., \& Kentta, G. (2020). Psychological distress and problem gambling in elite athletes during COVID-19. Restrictions - A Web survey in top leagues of three sports during the pandemic. International Journal of Environmental Research and Public Health, 17(18): 6693. https://www.mdpi.com/1660-4601/17/18/6693/htm

Hermassi, S., Bouhafs, E. G., Bragazzi, N. L., Ichimura, S., Alsharji, K. E., Hayes, L. D., \& Schwesig, R. (2020). Effects of home confinement on the intensity of physical activity during the COVID-19 outbreak in team handball according to country, gender, competition level and playing position: A worldwide study. International Journal of Environmental Research and Public Health, 18(8): 4050. https://doi.org/10.3390/ijerph18084050

Kucheryavenko, V. V., \& Beletskaya, O. S. (2020). From shutdown to swoosh. The linguistic fallout of coronavirus crisis in economic discourse. European Proceedings of Social and Behavioural Sciences, 97, 554-563. https://doi.org/10.15405/epsbs.2020.12.02.74 
Memish, Z. A., Steffen, R., White, P., Dar, O., Azhar, E. I., Sharma, A., \& Zumla, A. (2019). Mass gatherings medicine. Public Health issues arising from mass gathering religious and sporting events. The Lancet, 393(10185), 2073-2084. https://doi.org/10.1016/S0140-6736(19)30501-X

Mon-Lopez, D., de la Rubia Riaza, A., Galan, M. H., \& Roman, I. R. (2020). The impact of Covid-19 and the effect of psychological factors on training conditions of handball players. International Journal of Environmental Research and Public Health, 17(18): 6471. https://doi.org/10.3390/ijerph17186471

Ogasawara, I., Hamaguchi, S., Hasegawa, R., Akeda, Y., Ota, N., Revankar, G. S., Konda, S., Taguchi, T., Takanouchi, T., Imoto, K., Okimoto, N., Sakuma, K., Uchiyama, A., Yamasaki, K., Higashino, T., Tomono, K., \& Nakata, K. (2021). Successful reboot of high-performance sporting activities by Japanese national women's handball team in Tokyo 2020 during the COVID-19 pandemic: An initiative by Japan Sports-Cyber Physical System (JS-CPS) of Sports Research Innovation Project (SRIP). International Journal of Environmental Research and Public Health, 18(18): 9865. https://doi.org/10.3390/ijerph18189865

Perlman, S. (2020). Another decade, another virus. The New England Journal of Medicine, 382(8), 760-762. https://doi.org/10.1056/nejme2001126

Ratten, V. (2020). Coronavirus disease (COVID-19) and sport entrepreneurship. International Journal of Entrepreneurial Behavior \& Research, 26(6), 1379-1388. https://doi.org/10.1108/IJEBR-06-2020-0387

Setiawan, E., Iwandana, D. T., Festiawan, R., \& Baptista, C. (2020). Improving handball athletes' physical fitness components through Tabata training during the outbreak of COVID-19. Jurnal sportif: Jurnal Penelitian Pembelajaran, 6(2), 375-389. https://doi.org/10.29407/js_unpgri.v6i2.14347

Tsiring, D., \& Ponomareva, I. (2021). Emotional state of region's residents during the emergency pandemic of coronavirus. European Proceedings of Social and Behavioural Sciences, 339-346. http://dx.doi.org/10.15405/epsbs.2021.04.37

World Health Organization. (2019). Coronavirus disease 2019 (COVID-19). Situation report - 43. https://www.who.int/docs/default-source/coronaviruse/situation-reports/20200303sitrep-43-covid-19.pdf?sfvrsn=2c21c09c_2 